\title{
STUDY OF GIBBERELLIC ACID PRODUCTION BY SOLID STATE FERMENTATION USING FUSARIUM MONILIFORME SHELDON
}

\author{
Rakeshkumar R. Panchal ${ }^{1 *}$ and Piyushbhai V. Desai ${ }^{2}$ \\ ${ }^{1}$ Department of Microbiology, M. B. Patel science college, Anand, India \\ ${ }^{2}$ Department of Biosciences, Veer Narmad South Gujarat University, Surat, India \\ *Corresponding author's email: panchalrrce@yahoo.com
}

\begin{abstract}
Gibberellic acid production using Fusarium moniliforme, isolated from wilted sugarcane plant has been investigated by solid state fermentation (SSF). The gibberellic acid production of $154 \mu \mathrm{gm} / \mathrm{gm}$ was obtained on commercial wheat bran (CWB) mineral salt acid bed in $500 \mathrm{ml}$ flasks after $168 \mathrm{~h}$ incubation. The gibberellic acid production rate was about 0.6 to $0.9 \mu \mathrm{gm} / \mathrm{gm} / \mathrm{hr}$ during 96 to $168 \mathrm{~h}$. Different carbon sources namely sucrose, lactose, maltose, soluble starch, glycerol, wheat flour and maize flour were tested as an additional substrate along with CWB at the concentration of $25 \% \mathrm{w} / \mathrm{w}$ or $\mathrm{v} / \mathrm{w}$ base to observe its effects on gibberellic acid production. Soluble starch has been proved the best additional carbon source for gibberellic acid production, which yielded $1160 \mu \mathrm{gm} / \mathrm{gm}$ of gibberellic acid after $168 \mathrm{~h}$. Similarly, various nitrogen sources namely $\mathrm{NH}_{4} \mathrm{Cl}, \mathrm{NH}_{4} \mathrm{NO}_{3},\left(\mathrm{NH}_{4}\right)_{2} \mathrm{SO}_{4},\left(\mathrm{NH}_{4}\right) \mathrm{MoO}_{4}$ and urea were tested as an additional substrate at the concentration of $0.07 \%$ w/w of CWB. Urea was proved as the best nitrogen source which yielded $532 \mu \mathrm{gm} / \mathrm{gm}$ of gibberellic acid after $168 \mathrm{~h}$ incubation. We have observed about 7.5-fold and 3.5-fold increase in gibberellic acid production upon addition of soluble starch and urea respectively, in CWB using Fusarium moniliforme.
\end{abstract}

Keywords: Fusarium moniliforme; Gibberellic acid; Wheat bran; Maize flour; Dry moldy bran.

\section{Introduction}

A group of diterpenoid acids termed as Gibberellic acids (GAs) are largely produced by Fusarium moniliforme which is earlier known as Gibberella fujicuroi, and functions as growth regulators of plants. GAs influences a wide range of development processes in plants which includes dormancy, germination, stem elongation, sex expression, flowering, induction of enzymes and leaf and fruit senescence. The origin of research in to gibberellins can be traced to Japanese plant pathologists who were investigating the causes of the 'bakanae' (foolish seedling) disease which seriously lowered the yield of rice crops in Japan, Taiwan and throughout the Asian continent (Kurosawa, 1926).

The first paper on the cause of bakanae was published in 1898 by Shotaro Hori who demonstrated that the symptoms were induced by infection with a fungus belonging to the genes Fusarium, probably Fusarium heterosporium Nees. Subsequently, Elichi Kurosawa (1926) found that culture filtrates from dried rice seedlings caused marked elongation in rice and other sub-tropical grasses. He concluded that bakanae fungus secretes a chemical that stimulates shoot elongation, inhibits chlorophyll formation and suppresses root growth.

Teijiro Yabuta initiated work on the isolation of the active component using the fungal strains provided by Kurosawa. As a result, non-crystalline solid was obtained from the culture filtrate that stimulated the growth of rice seedlings. This compound was named gibberellin by Yabuta in 1935; the first use of the term 'gibberellin' in the scientific literature (Yabuta, 1938).

In 1938, Yabuta and his associate Yusuke Sumiki finally succeeded in crystallizing a pale yellow solid to yield gibberellin $\mathrm{A}\left(\mathrm{C}_{22} \mathrm{H}_{26} \mathrm{O}_{7}\right)$ and gibberellin- $\mathrm{B}\left(\mathrm{C}_{19} \mathrm{H}_{22} \mathrm{O}_{3}\right)$ (Yabuta and Sumiki, 1938). The names were subsequently inter changed in 1941 and the original gibberellin A was found to be inactive.

In the United States, the first research on gibberellins began after the Second World War by a research unit at Camp Dietrick, Maryland. In 1950, John E. Mitchell reported optimal fermentation procedures for the fungus, as well as the effects of fungal extracts on the growth of bean (Vicia faba) seedlings (Mitchell \& Angel, 1951). Work also began at the Northem USDA Regional Research Laboratories in Peoria, llinois in the USA using the strain provided by 
Mitechell. Large scale fermentations were carried out with the purpose of producing pure gibberellin A for agriculture but initial fermentations were inactive.

The problem was traced to the lack of magnesium in the culture medium and good yields of gibberellin were obtained when the culture-medium was supplemented with magnesium sulphate. The physical properties of gibberellin isolated from these fermentations were found to be surprisingly different from those reported by the Japanese and the new compound was named gibberellin-X. (Stodola et.al., 1955).

At about the same time in the UK, a team of researchers at Akers Research Laboratories (ICI) isolated a new gibberellin which was given the name "Gibberellic acid". This compound had physical properties different from the Japanese gibberellin-A (Curtis \& Cross, 1954). Samples were exchanged between Stodola and Grove and "Gibberellic acid" and gibberellin-X were found to have identical chemical and physical properties and the name Gibberellic acid was accepted by both groups. A structure for Gibberellic acid was proposed in 1956 but later revised (Grove, 1961).

Fermentation mechanism of GA production is very complex as it is a secondary metabolite.

Kumar and Lonasane (1987) studied the gibberellic acid production by solid state fermentation (SSF) and submerged fermentation (SMF). The study indicated better productivity with the former technique. The accumulation of $\mathrm{GA}_{3}$ was 1.626 times higher in the case of SSF on the basis of available carbohydrate in the media. The percent conversions were 0.096 and 0.156 in SMF and SSF respectively. The use of coarse wheat bran of the particle size of 0.3 to $0.4 \mathrm{~cm}$. resulted in an increase of 2.5 times in the yield of $\mathrm{GA}_{3}$. The enrichment of commercial wheat bran with soluble starch gave enhanced accumulation to an extent of 3.5 times. The relation between $\mathrm{GA}_{3}$ production and cell growth in SSF was similar to that in SMF. On preliminary cost analyses a net savings of about $60 \%$ and $50 \%$ on fermentation medium cost and the expenditure on downstream processing, respectively.

Tomasini et al. (1997) studied gibberellic acid production in liquid fermentation and compared it with production of gibberellic acid in solid state fermentation system using cassava flour, sugarcane bagas and low density polyurethane. Gibberella fujikuroi produced $23 \mathrm{mg}$ of gibberellin /ml in $120 \mathrm{hr}$. of liquid fermentation. Solid state fermentation on bagas showed excellent growth but presented gibberellin extraction problems. Very low production and growth was observed in solid state fermentation with low density polyurethane as an inert support. Solid state fermentation on cassava flour showed high production, $250 \mathrm{mg} / \mathrm{kg}$ of dry solid medium in a very short time (36 hr.).
Kumar and Lonsane (1988) worked on the batch and fed batch solid state fermentation with a fermentor operation strategy based on constant or intermittent feed streams and containment of the product in the fermentor up to the end of the run. In a fed batch solid state fermentation involving the feeding of corn starch during idiophase, the rate and quantities of production of Gibberellic acid, dry cell mass and proteases were higher than those in batch solid state fermentation.

Kumar and Lonsane (1990) have studied the effect of physical and nutritional factors on gibberellic acid production in solid state fermentation. The nutritional factors studied were the urea nitrogen and magnesium sulfate concentrations, whereas the physical factors were moisture content, autoclaving time, inoculum ratio and moist medium to culture flask volume ratio. The yield of gibberellic acid was improved 2.9 times by optimization of these parameters. This has increased the gibberellic acid yield in the wheat bran medium and resulted in reduction of the overall cost of production.

Qian et al. (1994) worked on the production of gibberellic acid (GA) by $F$. moniliforme in solid state culture in flask culture as wells as in horizontal rotary reactor. The highest production rate of Gibberellic acid was observed with $80 \%$ maize flour mixed with wheat bran. The optimum initial moisture depends inversely on the ambient relative humidity. A low oxygen concentration resulted in a much decreased gibberellic acid yield and the appearance of a yellow to reddish pigment in the mycelium. The lag phase was short and rapid growth continued for up to 2 days in the rotary reactor, with a maximum specific growth rate of 0 $12^{-\mathrm{h}}$. The maximum rate of gibberellic acid production occur during the subsequent 3 to 10 days of incubation and final gibberellic acid $\mathrm{GA}_{3}$ concentration reached was 18.7 $\mathrm{mg} / \mathrm{g}$ dry weight. The maximum Gibberellic acid accumulation after 10 to 12 days of incubation was usually marked by sharp increase in $\mathrm{pH}$.

\section{Materials and Methods}

Gibberellic Acid Production by Solid State Fermentation Gibberellic acid production by solid state fermentation was done using the method described by Kumar and Lonsane (1987).

\section{Inoculum Phase}

The inoculum was grown on Czapek Dox liquid medium by adding $10^{6}$ spores of $F$. moniliforme / $\mathrm{ml}$ of medium (100 $\mathrm{ml}$ medium in $250 \mathrm{ml}$ Erlenmayer flasks) and grown on rotary shaker at $150 \mathrm{rpm}$ at $30^{\circ} \mathrm{C}$ for 48 hours.

\section{Production Phase}

The production medium containing commercial wheat bran (containing about $8.5 \%$ starch on dry weight basis) was prepared. 
$25 \mathrm{gm}$ moist medium was charged per $500 \mathrm{ml}$ Erlenmayer flasks, eight flasks were prepared from $80 \mathrm{gm}$ commercial wheat bran. All flasks were autoclaved at $121^{\circ} \mathrm{C}$ for one hour, cooled to room temperature and inoculated with 3.75 $\mathrm{ml}$, per flask, of homogenized $48 \mathrm{~h}$ grown culture. All the flasks were incubated in slanting position at $28 \pm 1^{\circ} \mathrm{C}$ for 7 days and samples were analyzed for the $\mathrm{GA}_{3}$ level at every 24 hours. A set of seven flasks had been inoculated and every day one flask was used for analytical work.

\section{Extraction of $\mathrm{GA}_{3}$}

After completion of fermentation the moldy bran (MB) was dried at $40^{\circ} \mathrm{C}$ to obtain dry moldy bran (DMB). $\mathrm{GA}_{3}$ was extracted from DMB with ethyl acetate in three stages using $10 \mathrm{ml}$ each to obtain total $30 \mathrm{ml}$ extract. This $30 \mathrm{ml}$ ethyl acetate extract was further evaporated to $5.0 \mathrm{ml}$ and used for estimation purpose.

\section{Estimation of $\mathrm{GA}_{3}$ by Spectrophotometric Technique}

For estimation of $\mathrm{GA}_{3}$ the spectrophotometric method described by Berrios et. al. (2004) at $254 \mathrm{~nm}$ was used.

\section{Enrichment of Commercial Wheat Bran with Different Carbon and Nitrogen Sources}

The method described by Kumar and Lonsane (1987) and (1990) was used for the enrichment studies.

The effect of enrichment of commercial wheat bran with seven different carbon sources were studied at $25 \%$ level (w/w or $\mathrm{v} / \mathrm{w}$ ) based on the weight of commercial wheat bran.

Water insoluble carbon sources viz. wheat flour and maize flour were thoroughly mixed with wheat bran before moistening. Heat sensitive carbon substrates such as sucrose, lactose and maltose were sterilized at $10 \mathrm{lb}$ pressure for 15 minutes and were added to the sterilized wheat bran medium before inoculation, while the water soluble carbon substrates such as soluble starch and glycerol were dissolved in mineral salt solution and then used for moistening wheat bran.

For enrichment of nitrogen sources commercial wheat bran medium was enriched with $70 \mathrm{mg}$ nitrogen from different sources per $100 \mathrm{gm}$ commercial wheat bran. Desired weight of different nitrogen sources except urea were dissolved in mineral salt solution and then used for moistening wheat bran. The urea solution of desired concentration was sterilized by passing through a bacteriological filter and was added to the sterilized medium at the time of inoculation.

\section{Results and Discussion}

\section{$\mathrm{GA}_{3}$ Production by SSF on WB Medium}

The amount of $\mathrm{GA}_{3}$ produced by SSF on WB medium is shown in Table 1 and Fig. 1. For the initial 3 days the production is negligible or the amount produced is not sufficient enough to be detected by the method used the maximum $\mathrm{GA}_{3}$ production was observed on the $7^{\text {th }}$ day and thereafter it remained unchanged on the $8^{\text {th }}$ day. There was gradual increase in the production and the rate of production from $4^{\text {th }}$ day onwards. The rate of production was maximum on the $7^{\text {th }}$ day but it declined on the $8^{\text {th }}$ day. Although cell biomass estimation was not carried out, from the results we could say that the culture must have grown in the log phase in the initial $72 \mathrm{hrs}$ and then the growth was in the stationary phase until the end of the fermentation experiment. The production phase may thus coincide with the stationary phase.

A similar pattern of $\mathrm{GA}_{3}$ production was observed with the five strains of $F$. moniliforme studied by Kumar and Lonsane (1987). In G. fujikuroi isolated from rice plants the production of $\mathrm{GA}_{3}$ was initiated after $72 \mathrm{hrs}$ and reached to maximum on $7^{\text {th }}$ day (Kumar and Lonsane 1988).

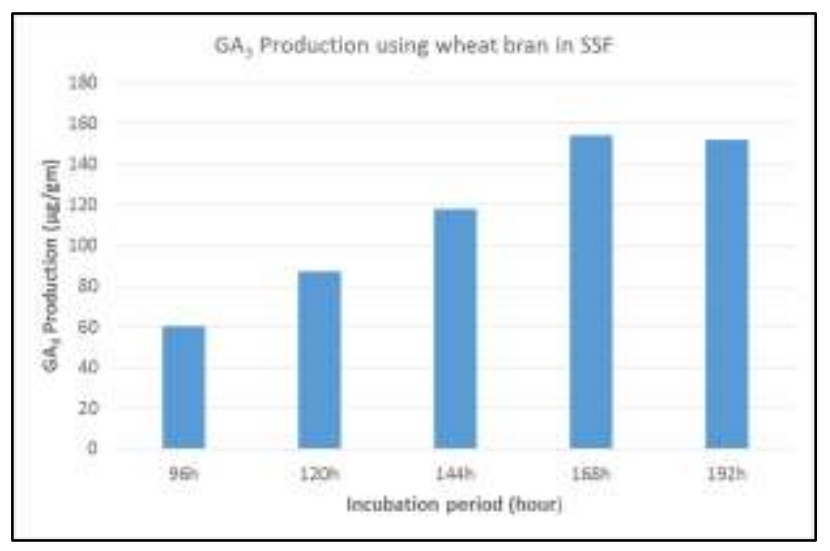

Fig. 1: $\mathrm{GA}_{3}$ Production using wheat bran in SSF medium

Table 1: Rate of GA3 productions by solid state fermentation on commercial Wheat bran medium

\begin{tabular}{|l|l|}
\hline $\begin{array}{l}\text { Incubation period } \\
\text { (hours) }\end{array}$ & $\begin{array}{l}\text { Rate of GA3 Production } \\
(\boldsymbol{\mu g} / \mathbf{g m} / \mathbf{h})\end{array}$ \\
\hline 96 & 0.625 \\
\hline 120 & 0.725 \\
\hline 144 & 0.819 \\
\hline 168 & 0.916 \\
\hline 192 & 0.791 \\
\hline
\end{tabular}

Note: 10 gm commercial wheat bran was taken / flask.

\section{Effect of Supplementary Carbon Sources on $\mathrm{GA}_{3}$ Production by SSF in CWB Medium}

The effect of enrichment to CWB with seven different carbon sources is shown in Fig. 2. When the $\mathrm{GA}_{3}$ production was observed on $5^{\text {th }}, 6^{\text {th }}$ and $7^{\text {th }}$ day, there was remarkable improvement in the $\mathrm{GA}_{3}$ production with all the carbon sources. Soluble starch was found to be the best enrichment source. There was about a 7 to 8 fold increase in the $\mathrm{GA}_{3}$ production when CWB was enriched with soluble starch. With other carbon sources there was about 3 to 4 fold increase except lactose. The increase in $\mathrm{GA}_{3}$ production 
with lactose was very little on $5^{\text {th }}$ and $6^{\text {th }}$ day; however, the increase on $7^{\text {th }}$ day was very high. The increase in $\mathrm{GA}_{3}$ production may be in direct correlation with the complexity of the carbon sources. Soluble starch being polysaccharide proved to be very effective for $\mathrm{GA}_{3}$ production. In case of disaccharides, Sucrose and maltose on hydrolyses give similar hexose sugars, supported the production equally on $5^{\text {th }}, 6^{\text {th }}$ and $7^{\text {th }}$ day. Lactose, giving glucose and galactose on hydrolyses, initially gave little increase but on $7^{\text {th }}$ day considerable increased in $\mathrm{GA}_{3}$ production was observed. Natural sources like maize and wheat flour supported higher production of $\mathrm{GA}_{3}$ but the increase in $\mathrm{GA}_{3}$ production is less compare to the soluble starch. This may be due to the difference in structure of starch in the natural sources. Results obtained are well supported by the data obtained by Kumar and Lonsane (1987). In their studies $\mathrm{GA}_{3}$ production by $G$. fujikuroi was increased when CWB was enriched with twelve different carbon sources. The effect of enrichment with sucrose showed decrease in $\mathrm{GA}_{3}$ production in the later stages. They also studied the effect of enrichment with natural sources such as Sorghum flour, Maize flour and rice bran. The yield was reduced with rice bran because of the poor growth.

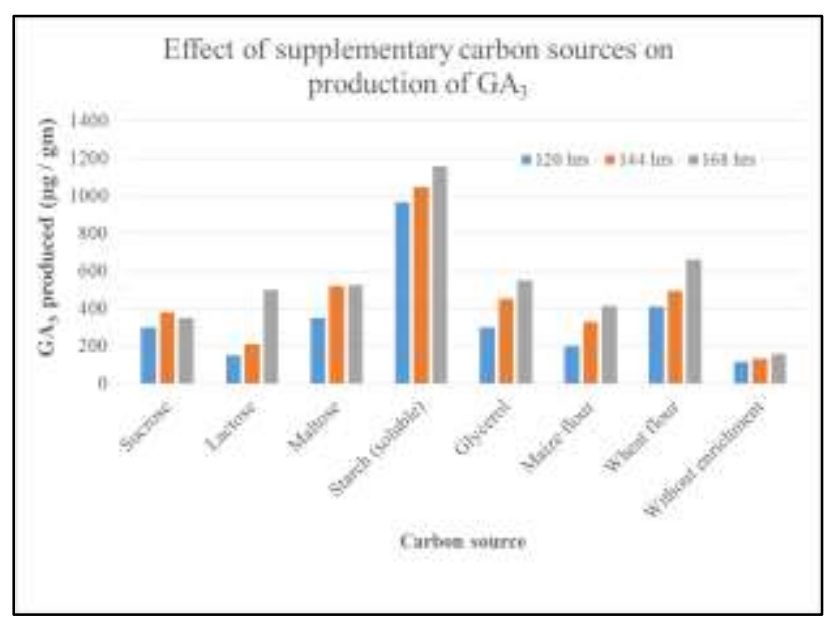

Fig. 2: Effect of supplementary carbon sources to CWB on production of $\mathrm{GA}_{3}$ by $\mathrm{SSF}$

\section{Effect of Supplementary Nitrogen Sources on GA3 Production by SSF in CWB Medium}

Results obtained for different nitrogen compounds used as supplementary sources are shown in Table 2. It was observed that the $\mathrm{GA}_{3}$ production with urea, which was used in the control, remains as a better source of nitrogen as compared to other ammonium sources studied.

The lower production of $\mathrm{GA}_{3}$ with ammonium salts may be due to the decrease in $\mathrm{pH}$ with the utilization of $\mathrm{NH}_{4}{ }^{+}$ions. This may not be favorable for the growth and production of $\mathrm{GA}_{3}$. Urea as nitrogen source also exhibit buffering activity and thus resists the change in $\mathrm{pH}$ during the course of its utilization. Although ammonium salts are costly compared to urea, our aim was to see the comparative level of GA3 production. If more $\mathrm{GA}_{3}$ production can be obtained the ultimate production cost of $\mathrm{GA}_{3}$ may be reduced. Amongst ammonium compounds, $\mathrm{NH}_{4} \mathrm{Cl}$ gave better production of $\mathrm{GA}_{3}$.

Urea proved to be better source. This was also reported by Kumar and Lonsane (1990). They also studied the effect of different concentrations of urea on $\mathrm{GA}_{3}$ production by $\mathrm{G}$. fujikuroi. There was an increase in production of $\mathrm{GA}_{3}$ with the increase in concentration of urea in the range of 10 to 70 $\mathrm{mg} \%$. There was decrease in the $\mathrm{GA}_{3}$ production above 70 mg $\%$ concentration.

Table 2: Effect of supplementary nitrogen sources to CWB on production of $\mathrm{GA}_{3}$ by SSF.

\begin{tabular}{|l|l|l|l|}
\hline \multirow{2}{*}{ Nitrogen sources } & \multicolumn{3}{|c|}{ GA3 production in CWB } \\
& \multicolumn{3}{|c|}{$\boldsymbol{\mu g} /$ gm $)$} \\
\cline { 2 - 4 } & \multicolumn{3}{|c|}{ Incubation period } \\
\cline { 2 - 4 } & $120 \mathrm{hrs}$ & $144 \mathrm{hrs}$ & $168 \mathrm{hrs}$ \\
\hline $\mathrm{NH}_{4} \mathrm{Cl}$ & 190 & 302 & 391 \\
\hline $\mathrm{NH}_{4} \mathrm{NO}_{3}$ & 140 & 212 & 280 \\
\hline$\left(\mathrm{NH}_{4}\right)_{2} \mathrm{SO}_{4}$ & 120 & 160 & 230 \\
\hline $\mathrm{NH}_{4} \mathrm{M}_{4} \mathrm{OO}_{4}$ & 110 & 145 & 190 \\
\hline Urea & 234 & 489 & 532 \\
\hline Without enrichment & 95 & 125 & 163 \\
\hline
\end{tabular}

\section{Summary}

The isolated culture was tested for the production of the gibberellic acid by solid state fermentation on wheat bran mineral salt acid bed in $500 \mathrm{ml}$. flasks, where considerable amount of gibberellic acid was obtained. Different carbon sources were added as additional substrate along with CWB viz Sucrose, Lactose, Maltose, Starch (soluble), Glycerol, wheat flour, Maize flour were tested for production of gibberellic acid. Soluble starch proved to be the best additional substrate for gibberellic acid production. Similarly various nitrogen sources viz. $\mathrm{NH}_{4} \mathrm{CL}, \mathrm{NH}_{4} \mathrm{NO}_{3}$, $\left(\mathrm{NH}_{4}\right)_{2} \mathrm{SO}_{4},(\mathrm{NH})_{4} \mathrm{MoO}_{4}$ and urea were tested for its effect on gibberellic acid production, where urea proved to be the best nitrogen source.

\section{Acknowledgements}

We are thankful to the Head, department of biosciences, Veer Narmad South Gujarat University and Management and Principal of M.B.Patel Science College, Anand for providing all the facilities for the present work.

\section{References}

Berrios J, Illanes A and Aroca G (2004) Spectrophotometric method for determining gibberellic acid in fermentation broths. Biotechnology letters 26(1): 67-70.DOI: 10.1023/B:BILE.0000009463.98203.8b

Cross BE (1959) A revised structure for gibberellic acid. Proc. Chem. Soc.: $302-303$. 
Curtis PJ and Cross BE (1954) Gibberellic acid- A new metabolite from the culture filtrate of Gibberella fujikuroi. Chem. Ind. 35: 1066 .

Grove JF (1061) The gibberellins. Quart. Rev. (Chem. Soc. London). 15: 46-70.

Holbrook AA (1961) Spectrophotometeric method for detection of gibberellic acid. Advances in chemistry series. 28: $159-$ 167. DOI: $10.1021 /$ ba-1961-0028.ch018

Kumar P and Lonsane BK (1987) Gibberellic acid by solid state fermentation: consistent and improved yields. Biotechnology and Bioengineering 30(2): 267-271. DOI: 10.1002/bit.260300217

Kumar PKR (1987) Extraction of Gibberellic acid from dry moldy bran produced under solid state fermentation. Process biochem.: $139-143$.

Kumar PKR (1987) Gibberellic acid by solid state Fermentation: Consistent and improved yields. Biotech. Bioeng. 30: 267271. DOI: $10.1002 /$ bit.260300217

Kumar PKR (1988) Batch and fed batch solid state fermentations: kinetics of cell growth, hydrolytic enzymes production and Gibberellic acid production. Process biochem. 23(2): 43 47.

Kumar PKR and Lonsane BK (1990) Solid state fermentation: physical and nutritional factors influencing gibberellic acid production. Applied microbiology and biotechnology 34(2): 145-148. DOI: 10.1007/BF00166770

Kurosawa E (1026) Experimental studies on the nature of the substance secreted by the "bakanae" fungus. Nat. Hist. Soc. Formosa 16: 213- 227.

Mitchell JE and Angel CR (1951) The growth - stimulating properties of a metabolic product of Phaseolus multiforus. Phytopath. 41: 26-27.

Qian XM, Du Preez JC and Kilian SG (1994) Factors affecting gibberellic acid production by Fusarium moniliforme in solid-state cultivation on starch. World Journal of Microbiology and Biotechnology 10(1): 93-99. DOI: 10.1007/BF00357571

Stodola FH, Raper KB, Fennell DI, Conway HF, Sohns VE et al. (1955) The microbial production of gibberellins A and X. Arch. Biochem. Biophys. 54: 240-245. DOI: 10.1016/0003-9861(55)90027-8

Tomasini A, Fajando C and Barcos G (1997) Gibberellic acid production using different solid state fermentation systems. World J. MIcrobiol. Biotech. 13(2): 203 -206. DOI: 10.1023/A:1018545932104

Yabuta T and Sumiki Y (1938) On the crystal of gibberellin, a substance to promote plant growth. J. Agric. Chem. Soc. Japan 14: 1526.

Wheat bran medium for solid state fermentation of Gibberellic acid (Kumar and Lonsane , 1987): 
R.R. Panchal and P.V. Desai (2016) Int J Appl Sci Biotechnol, Vol 4(3): 402-407

\begin{tabular}{|l|l|}
\hline Commercial Wheat Bran & $80 \mathrm{gm}$ \\
\hline Soluble starch & $20 \mathrm{gm}$ \\
\hline Linseed Oil & $1.0 \mathrm{ml}$ \\
\hline Urea & $0.15 \mathrm{gm}$ \\
\hline Magnesium Sulphate & $0.007 \mathrm{gm}$ \\
\hline
\end{tabular}

The medium was moistened with $85 \mathrm{ml}$ of mineral salts solution in $0.2 \mathrm{~N}$. $\mathrm{HCl}$ which contained the following salts.

\begin{tabular}{|l|l|}
\hline $\mathrm{ZnSO}_{4} .7 \mathrm{H}_{2} \mathrm{O}$ & $0.007 \mathrm{gm}$ \\
\hline $\mathrm{CuSO}_{4} .5 \mathrm{H}_{2} \mathrm{O}$ & $0.007 \mathrm{gm}$ \\
\hline $\mathrm{FeS}_{4} .7 \mathrm{H}_{2} \mathrm{O}$ & $0.007 \mathrm{gm}$ \\
\hline Concentrated $\mathrm{HCl}$ & $16.9 \mathrm{ml}$ \\
\hline Distilled Water & $83.1 \mathrm{ml}$ \\
\hline
\end{tabular}

This solution was diluted 10 times before use.

$25 \mathrm{gm}$ moist medium was charged per $500 \mathrm{ml}$ Erlenmayer flasks, eight flasks were prepared from $80 \mathrm{gm}$ commercial wheat bran. All flasks were autoclaved at $121^{\circ} \mathrm{C}$ for one hour. 